\title{
Psicologia Clínica Existencialista na Atenção Básica à Saúde: Um Relato de Atuação
}

Existencialist Clinical Psychology in Basic Attention: An Intervention Report

Psicología Clínica Existencialista en la Atención Básica a la Salud: Un Relato de Actuación
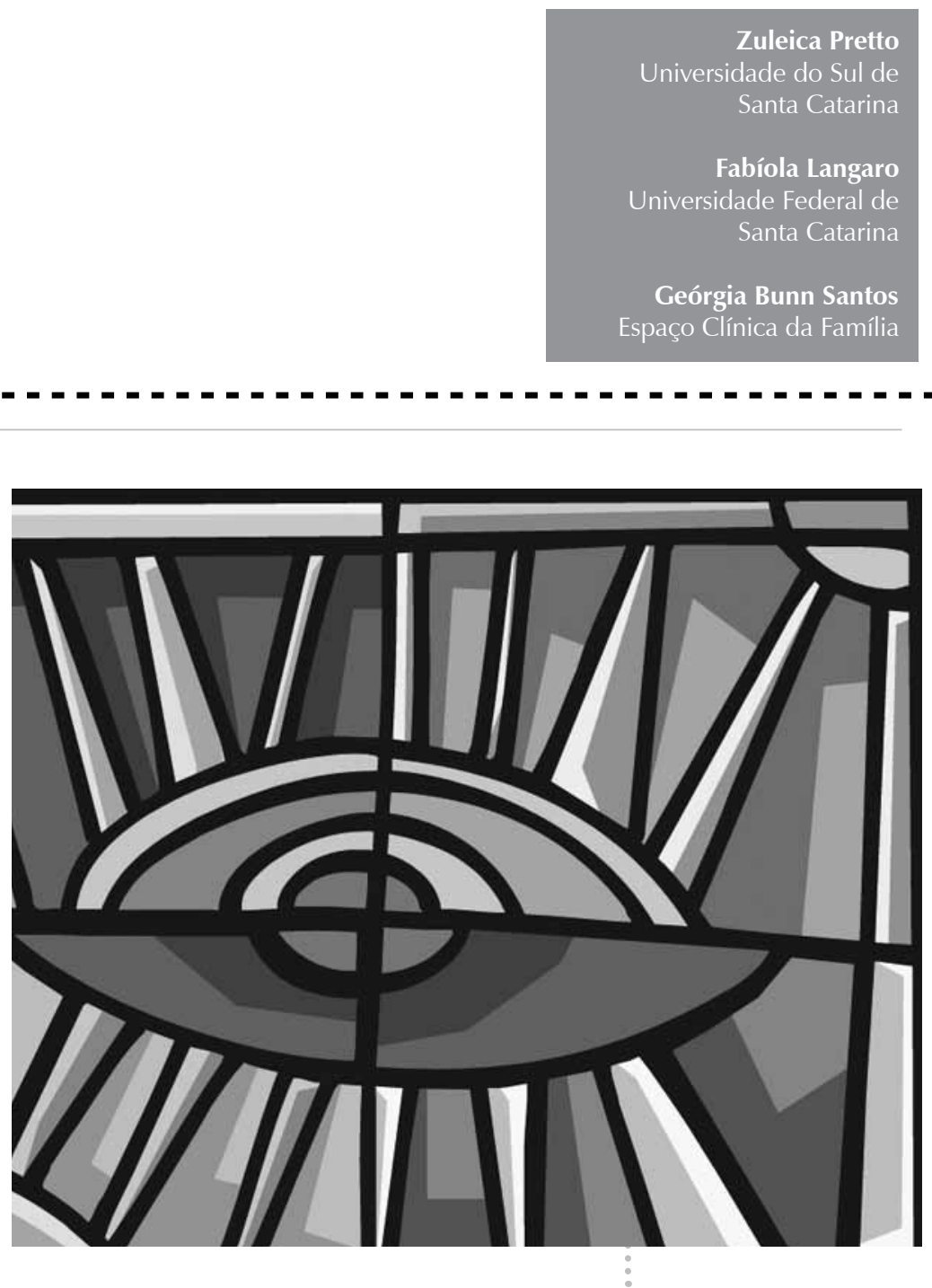
Resumo: A proposta deste artigo é compartilhar uma experiência de intervenção em Psicologia clínica a partir da abordagem existencialista de Jean-Paul Sartre, realizada em uma clínica integrada de atenção básica à saúde vinculada ao Sistema Único de Saúde (SUS), na Grande Florianópolis. O objetivo do atendimento psicológico é criar condições, junto aos sujeitos, para que sejam capazes de superar dificuldades, e auxiliálos a reconstruir seus projetos de ser. A demanda da clínica é diversificada - crianças, adolescentes, adultos, idosos e famílias -, e existem queixas de diferentes ordens, como dificuldades na aprendizagem, nas relações familiares, nas relações amorosas, na sexualidade e dificuldades provenientes de doenças orgânicas, de violência física e sexual e de psicopatologias variadas. Em sua atuação, considera-se que, do profissional que trabalha em uma unidade básica de saúde, é exigida uma diversidade de instrumentos teóricos e metodológicos e que a abordagem existencialista de Jean-Paul Sartre tem a possibilidade de abarcar, pela amplitude de sua teoria e de sua metodologia, as diferentes exigências apresentadas.

Palavras-chave: Sistema Único de Saúde (SUS). Atenção básica. Psicologia clínica. Existencialismo.

Abstract: The proposal of this article is to share an experience of intervention in clinical psychology based on Jean-Paul Sartre's existentialist approach, held in an integrated clinic of basic health which is linked to the Brazilian Unique Health System (SUS), in Florianópolis, SC. The objective of the psychological attendance is to create conditions, together with the subjects, to make them capable of overcoming difficulties and rebuilding their fundamental projects. The clinical demand is diversified - children, adolescents, adults, elderly and families - , and includes different complaints, such as learning difficulties, problems related to family relationships, love relationships, sexuality, organic diseases and difficulties that involve physical and sexual violence and several psychopathologies. In this context, it is assumed that the professional who works in a health basic unit should have a great amount of theoretical and methodological instruments and that Jean-Paul Sartre's existentialist approach has made possible to comprehend, by the width of his theory and methodology, the various requirements presented.

Keywords: Brazilian Unique Health System (SUS). Basic attention. Clinical psychology. Existentialism.

Resumen: La propuesta de este artículo es compartir una experiencia de intervención en Psicología clínica del abordaje existencialista de Jean-Paul Sartre, realizada en una clínica integrada de atención básica a la salud vinculada al Sistema Único de Salud (SUS), en la Gran Florianópolis. El objetivo del servicio psicológico es crear condiciones, junto a los sujetos, para que sean capaces de superar dificultades, y auxiliarles a reconstruir sus proyectos de ser. La demanda de la clínica es diversificado - niños, adolescentes, adultos, de edad y familias -, y existen quejas de diferentes clases, como dificultades en el aprendizaje, en las relaciones familiares, en las relaciones amorosas, en la sexualidad y dificultades provenientes de enfermedades orgánicas, de violencia física y sexual y de psicopatológicas variadas. En su actuación, se considera que, del profesional que trabaja en una unidad básica de salud, es exigida una diversidad de instrumentos teóricos y metodológicos y que el abordaje existencialista de Jean-Paul Sartre tiene la posibilidad de abarcar, por la amplitud de su teoría y de su metodología, las diferentes exigencias presentadas.

Palabras clave: Sistema Único de Salud (SUS). Atención básica. Psicología clínica. Existencialismo.

A abordagem existencialista de Jean-Paul Sartre permite refletir sobre as possibilidades de atuação da Psicologia a partir de uma concepção histórico-dialética de homem, segundo a qual o sujeito só pode ser compreendido mediante sua história individual e seu contexto social e cultural. Para tanto, tem-se como fundo de sustentação a noção de que o sujeito se faz e é feito no/ por esse conjunto de fatores (Sartre, 1978b), sendo possível, por isso mesmo, alterar sua personalidade conforme os acontecimentos que vivencia. Em muitos casos, porém, a alteração da personalidade apenas ocorre por meio de intervenções qualificadas, e o processo psicoterapêutico é uma delas.

A psicoterapia tem como função mediar o sujeito na construção de ferramentas que Ihe possibilitem alterar a situação de impasse em que se encontra. A idéia de mediação em Sartre está fundamentada no materialismo histórico-dialético, que compreende o desenvolvimento humano como resultado da atividade do indivíduo sobre seu meio. Desta forma, o homem age sobre as condições materiais e históricas em que está inserido, tornando-se produto e produtor da situação 
objetiva em que se insere e a partir da qual poderá, posteriormente, superar o que está dado. Para realizar esta atividade, o homem utiliza ferramentas mediadoras, que compõem o conjunto de instrumentos que dispõe para alterar sua condição. Neste sentido, a psicoterapia apresenta-se como um dos instrumentos que o indivíduo pode lançar mão para alterar suas condições objetivas e superar uma dada situação, fazendo-se diferente daquilo que se fez dele (Sartre, 1978b).

Visando atingir tal objetivo, a psicoterapia busca localizar o sujeito, isto é, situá-lo do modo como vivencia sua própria história, assim como pretende elucidar o contexto histórico-social em que está inserido e no qual vem constituindo sua personalidade. A partir disso, o sujeito terá condições de compreender como chegou a ser quem é naquele momento e, principalmente, que pode agir de forma a alterar o seu futuro, considerando que os sujeitos se caracterizam, fundamentalmente, pelo que ainda não são e, portanto, pela liberdade de se modificarem e modificarem o curso de suas vidas (Sartre, 1997). Isso ocorre na medida em que o psicoterapeuta utiliza instrumentos e técnicas - como a descrição dos eventos ocorridos ao longo da história do sujeito e a reflexão sobre ela - para assessorar o indivíduo nas mudanças desejadas.

A partir dessa perspectiva, atividades de Psicologia clínica vêm sendo oferecidas em uma Clínica Integrada de Atenção Básica à Saúde (CIABS) com o objetivo de oferecer atendimento psicoterápico gratuito à população que procura essa unidade básica, considerando que tal espaço fornece possibilidade de construção de intervenções diretas nas comunidades, visando a desenvolver estratégias pessoais e coletivas de enfrentamento das dificuldades relacionadas aos processos de saúde/doença. Este artigo se propõe, assim, a compartilhar tal experiência de intervenção em Psicologia clínica, a partir da abordagem existencialista de Jean-Paul Sartre, realizada em uma clínica integrada de atenção básica à saúde vinculada ao Sistema Único de Saúde (SUS), na Grande Florianópolis.

\section{Atuação da Psicologia clínica na Clínica Integrada de Atenção Básica à Saúde (CIABS)}

Fundamentados nessa perspectiva teórica, os atendimentos psicológicos têm sido realizados por estagiários de Psicologia em uma clínica integrada de atenção básica à saúde, desde o ano 2002. Fundada nesse mesmo ano, a clínica é caracterizada como um órgão de prestação de serviços de atenção básica à saúde, com vistas à promoção, proteção, recuperação e reabilitação da saúde da criança, do adolescente, da mulher, do adulto e do idoso, e está localizada no Município de Biguaçu, SC. Denominada CIABS - Clínica Integrada de Atenção Básica à Saúde, atende a comunidade residente na região próxima à clínica e também a comunidade universitária, através da disponibilidade de espaço para aprendizagem, tendo, assim, a função de clínica-escola. No segundo semestre de 2007, o quadro geral dos estagiários de Psicologia era de 27 alunos de Psicologia clínica, supervisionados por 10 professores de diferentes abordagens teóricas, e 5 estagiários de Psicologia educacional, supervisionados por 2 professores.

Além do atendimento psicológico, a CIABS oferece serviços médicos, odontológicos e de enfermagem, como curativos, vacinação, administração de medicamentos, nebulização, controle de pressão arterial e de diabetes, e outras atividades, como educação em saúde e visitas domiciliares. Através de uma parceria entre a fundação UNIVALI e a Secretaria Municipal de Saúde de Biguaçu, seus profissionais atendem, em média, 2.590 famílias, ou seja, uma população de cerca de 9.500 habitantes. A finalidade da clínica 
Tendo sido criado conforme a Constituição Federal (Brasil, 1988), o SUS "não é um serviço ou uma instituição, mas um Sistema que significa um conjunto de unidades, serviços e ações que interagem para um fim comum"

(Kujawa, Both, \& Brutscher, 2003, p. 24). é atender todas as pessoas de sua área de abrangência, indiscriminadamente, além de promover a formação do profissional da área da saúde através do desenvolvimento do ensino, da pesquisa e da extensão.

Como toda instituição pública de saúde, a organização e o funcionamento da clínica são orientados pelos princípios do Sistema Único de Saúde (SUS). Tendo sido criado conforme a Constituição Federal (Brasil, 1988), o SUS "não é um serviço ou uma instituição, mas um Sistema que significa um conjunto de unidades, serviços e ações que interagem para um fim comum" (Kujawa, Both, \& Brutscher, 2003, p. 24). O SUS tem como objetivo criar políticas públicas de saúde que integrem o campo de ação social do Estado, orientado para a melhoria das condições de saúde da população. Sua tarefa específica consiste em organizar as funções públicas governamentais para a promoção, a proteção e a recuperação da saúde dos indivíduos e da coletividade. Sua implantação é de responsabilidade da União, dos Estados e dos Municípios, e tem como princípios a universalidade (a saúde é direito de todos e dever do Estado), a integralidade (o ser humano é entendido como um todo e precisa ser atendido por um sistema que abranja tal todo) e a eqüidade no acesso às ações e aos serviços (Ministério da Saúde, 1990).

Segundo Kahhale (2003), quando o SUS começou a ser implantado no Brasil, as ações em saúde, conforme orientação da OMS, deveriam ser direcionadas para a sua promoção, a partir da criação de ações voltadas para a participação da comunidade, considerando-se a saúde um processo coletivo e possibilitando, portanto, o seu controle social. Além disso, tendo em vista que a saúde envolve uma atitude ativa dos indivíduos frente às dificuldades enfrentadas em seus aspectos biológicos, psíquicos e sociais, sua promoção seria possível apenas como projeto social, com o envolvimento de indivíduos, da comunidade e da sociedade em geral. Essa concepção de saúde é sedimentada a partir da compreensão de que a realidade humana é construída historicamente, mediante ações cotidianas e de mútua influência entre homens e mulheres, em qualquer espaço social em que estejam inseridos. Promover saúde envolve, além do seu aspecto biológico, a condição psicológica para lidar com os acontecimentos e uma formação cultural e política que garanta a conscientização de cada sujeito acerca de seus direitos e deveres: "o exercício do controle social é a democratização dos conhecimentos, estimulando a organização da sociedade para o efetivo exercício da democracia direta na gestão do Sistema Único de Saúde" (Kujawa et al., 2003, p. 31). Vale ressaltar que a promoção da saúde é um dos grandes desafios do SUS, uma vez que envolve outra lógica, que rompe a visão biologicista de saúde, bem como o predomínio e os privilégios dos serviços assistenciais.

Foi nesse contexto que a Psicologia teve sua inserção nas Unidades Básicas de Saúde. Segundo Kahhale (2003),

\footnotetext{
a inserção do psicólogo nos serviços públicos de saúde ocorre no momento em que, ao mesmo tempo, há um movimento geral das nações e, especificamente no Brasil, um movimento no interior da própria Psicologia, com o desenvolvimento da Psicologia social comunitária. (p. 184)
}

Nesse sentido, o trabalho do profissional no setor envolve "um processo de recriar sentidos e refazer projetos de vida, o que permitirá apropriação da subjetividade individual e social..." (Kahhale (2003, p. 188).

Apesar de existirem outras possibilidades de atuação da Psicologia nas Unidades Básicas de Saúde e junto ao Programa de Saúde da Família (PSF), ou seja, de capacitação de profissionais, de planejamento de ações em equipe e de realização de trabalhos de cunho educacional, 
entende-se que a Psicologia clínica ainda seja uma atividade importante a ser realizada pelo psicólogo nesse contexto, com a qual outros profissionais da área da saúde procuram contar. A importância da atuação da Psicologia nesse espaço está relacionada à busca da consolidação de uma compreensão ampliada de saúde, a partir da qual o sujeito encontra amparo e constrói ferramentas para lutar por sua saúde. Tal sujeito, conforme Canguilhem (1982), é considerado capaz de superar crises não apenas orgânicas mas também psicológicas e sociais, para instaurar uma nova organização na sua vida. Portanto, a partir dessa perspectiva, o trabalho de psicoterapia individual e familiar desenvolvido nesse campo de estágio teve como base a compreensão de que ser saudável significa ser capaz de participar do processo de construção da organização de eventos que acrescentem e garantam qualidade à vida das pessoas e, sobretudo, ao gerenciamento de suas vidas, na autoria e na assunção da responsabilidade por suas escolhas e na compreensão de uma abordagem biopsicossocial em saúde que os contemple em sua totalidade existencial.

Assim, tendo em vista a relevância da atuação da Psicologia clínica no âmbito da atenção básica à saúde, o enfoque proposto neste artigo é a discussão sobre o desenvolvimento do processo psicoterapêutico com base no existencialismo de Jean-Paul Sartre (1978a, 1978b, 1994, 1997) nesse campo de ação bem como na leitura de Schneider (2002) sobre a psicologia clínica sartreana. Tal enfoque, com seu conjunto de instrumentos metodológicos específicos, compreende o homem a partir de sua história e das relações que estabelece com seu meio, o que permite abarcar a diversidade dos fenômenos a serem trabalhados em psicoterapia; considera, ainda, o homem como aquele que se move para o futuro e que o faz em direção àquilo que ainda não é e que ainda pode realizar, possibilitando que o sujeito altere a condição de dificuldade que o levou a buscar o auxílio da Psicologia.

\section{A atuação da Psicologia clínica a partir do existencialismo de Jean-Paul Sartre}

Na CIABS - Clínica Integrada de Atenção Básica à Saúde -, a área de Psicologia tem organizado sua atuação prestando serviços a pessoas que procuram atendimento psicológico espontaneamente e/ou que são encaminhadas por outros profissionais da Unidade Básica de Saúde e pela equipe do PSF. A demanda pelo atendimento psicológico é caracterizada pela diversidade -crianças, adolescentes, adultos, idosos, mulheres, homens e famílias -, que se queixam de problemas de diferentes ordens, como dificuldades relacionadas à aprendizagem, à escola, às relações familiares, às relações amorosas, à sexualidade, às doenças, à violência física e sexual e às psicopatologias variadas. Tal diversidade tem exigido dinamicidade dos profissionais de Psicologia, bem como competência e habilidade teórica e metodológica que dêem conta de abarcar os fenômenos a serem trabalhados em psicoterapia. Essa exigência, decorrente dos trabalhos realizados na clínica, parece estar sendo atendida pela abordagem existencialista devido à amplitude de seus instrumentos disponíveis e pelo fato de essa concepção sustentar-se em uma compreensão de homem que é histórica, concreta e sempre atualizada, conforme as relações que ele estabelece (Castro \& Schneider, 1998; Sartre, 1978b; Schneider, 2002; Trafani, 1992).

Para o existencialismo, o homem é um ser-nomundo (Sartre, 1978a), o que significa que ele é dotado de um corpo e de uma consciência, através dos quais se relaciona com o meio, estabelecendo relações que caracterizam sua existência. A partir do estabelecimento das relações com os outros, que medeiam 
suas relações com as coisas, com o tempo e com seu próprio corpo, o homem tem a possibilidade de construir sua personalidade, de "essencializar-se" (Sponchiado, 1989).

Segundo Sartre (1978b), os seres humanos são seres sociais por excelência. A estrutura social em que o indivíduo está inserido fornece o horizonte no qual encontrará os parâmetros para construir sua singularidade, apropriandose ativamente de um conjunto de práticas sociais, de valores, de conhecimentos, de ideologias e de afetos histórica e culturalmente constituídos. Todas as mediações a que os indivíduos estão sujeitos, na medida em que vão se desenvolvendo, começam a ser apropriadas de forma reflexiva, constituindo, assim, a inteligibilidade que terão de si mesmos, ou seja, é através da reflexão que o sujeito estabelece um entendimento de como age, pensa e sente, sendo tal inteligibilidade construída pela apropriação singular que o sujeito elabora dos valores, dos conhecimentos e das crenças da sociedade, mediados pelas pessoas que o cercam.

É essa dialética entre a subjetividade e a objetividade que determinará a personalização dos indivíduos. Dessa forma, a constituição da personalidade ocorre como resultado do processo de subjetivação da objetividade e de objetivação da subjetividade, ou seja, da ação de interiorização da exterioridade que se consolida como uma subjetividade objetivada. Tal subjetividade é a totalização das relações que o sujeito estabeleceu com o mundo, que se objetiva através de seus estados, de suas ações e, facultativamente, de suas qualidades. Segundo Sartre (1994), os estados definem como o sujeito se experimenta, não sendo emoções momentâneas; através das suas ações, o sujeito tem seu ser definido. Finalmente, as qualidades são as unidades dos estados, e têm um caráter constitutivo mais permanente na personalidade do indivíduo.
Os indivíduos também se constituem a partir de suas escolhas, que estão sempre relacionadas a um projeto, a um desejo de ser. Suas escolhas cotidianas se relacionam a uma escolha essencial, que os leva a um projeto fundamental, caracterizado pela totalização em curso, que é o homem (Schneider, 2002). Para Sartre (1978b), "o homem define-se pelo seu projeto. Esse ser material supera perpetuamente a condição que lhe é dada; revela e determina sua situação, transcendendo-a para objetivar-se, pelo trabalho, pela ação ou pelo gesto" (p. 177), possibilitando-lhe estar sempre lançado para um determinado futuro. Entendendo que "a significação de qualquer desejo ou escolha empírica sempre transcende em direção ao projeto de ser" (Schneider, 2002, p. 192), e considerando que toda ação do homem o leva ao futuro e ao seu projeto, tem-se que, ao mover-se no mundo, o sujeito poderá se deparar com dificuldades que poderão inviabilizá-lo nesse projeto. Em tais momentos difíceis, em que o sujeito percebe seu projeto ameaçado, podem surgir complicações psicológicas. Assim, segundo Schneider (2002),

\begin{abstract}
a "complicação psicológica" é um acontecimento concreto na vida do sujeito, que o leva a experimentar uma "contradição de ser". A realidade the apresenta diferentes possibilidades, e seja qual for o lado para o qual se dirigir, seu ser está comprometido. (p. 291)
\end{abstract}

Qualquer complicação psicológica diz respeito justamente ao movimento do homem no mundo; assim, ela será compreendida na medida em que seja possível conhecer a história do sujeito, suas relações e a inteligibilidade que ele atribuiu às ocorrências experienciadas psicofisicamente. Será necessário, ainda, compreender como tal sujeito se construiu e como tem organizado seu movimento no mundo para que se 
demarque o que o levou a sentir-se inseguro quanto à realização de seu projeto de ser. Esse é o caminho que levará a um trabalho efetivo em psicoterapia, através do qual será possível transformar sua personalidade e superar as dificuldades enfrentadas, para que seu projeto seja revisto e reinventado.

Muitas vezes, contudo, o sujeito apenas consegue realizar mudanças e fazer escolhas mais críticas, ou seja, realizadas a partir de uma consciência posicional de si mesmo, quando o eu se torna objeto de reflexão, se uma nova mediação for inserida em suas relações. Dessa forma, a psicoterapia pode funcionar como uma nova mediação, favorecendo transformações e possibilitando ao sujeito a redefinição de seu projeto de ser. Tal método de intervenção tem demonstrado, no trabalho efetivado na clínica, que os sujeitos que procuram a psicoterapia têm se beneficiado, pois passam a localizar-se em sua história e na sua responsabilidade na construção da mesma e, em conseqüência, tornam-se mais reflexivos frente ao futuro desejado para si mesmos e às mudanças necessárias para a reformulação de seus projetos de ser (Schneider, 2002; Trafani, 1992).

\section{Especificidades da atuação}

No contexto da CIABS, algumas dificuldades cotidianas relacionadas principalmente ao comprometimento dos pacientes com o seu processo de psicoterapia ainda são encontradas, somadas ao fato de que, muitas vezes, quando chamados para o atendimento, não sentem mais necessidade do serviço de psicoterapia ou manifestam uma demanda diferente da expressada quando entraram na fila de espera, necessitando de outro encaminhamento. A população que busca atendimento psicológico na CIABS mora, predominantemente, em bairros populares do Município e conta com o benefício da gratuidade dos atendimentos em todas as áreas, inclusive da Psicologia. Muitas vezes, contudo, é preciso esperar pelo atendimento por um período de tempo que pode chegar até dois anos, em função da grande demanda e da quantidade reduzida de estagiários que trabalham na clínica, uma vez que não há profissionais de Psicologia contratados na equipe. Dessa forma, quando o contato é realizado para iniciar a psicoterapia, muitos não necessitam mais dos atendimentos ou, dando início a eles, abandonam as sessões em um período breve de tempo, com a justificativa de que seus interesses não contemplam mais a necessidade desse serviço. Essa última ocorrência pode estar relacionada ao desconhecimento da população sobre os instrumentos e os procedimentos utilizados na psicoterapia - haja vista que, historicamente, as camadas populares não tiveram acesso ao benefício do atendimento psicológico, essencialmente privado (Bock, 2003) -, o que cria uma lógica de resultados imediatos ou de soluções simples para os problemas que levam os sujeitos a procurar tal serviço.

Por outro lado, muitos pacientes demonstram grande interesse no início do processo psicoterápico, comparecendo assiduamente aos atendimentos, mas, em pouco tempo, abandonam as sessões, muitas vezes sem justificar sua desistência, ou, ainda, desistem devido à impossibilidade de horários - quando os horários da clínica são incompatíveis com os de seus trabalhos, por exemplo - ou mesmo devido à dificuldade de arcar com as despesas de locomoção até a CIABS. Tal característica da demanda tem gerado uma rotatividade bastante alta entre os pacientes atendidos pela Psicologia, o que prejudica o trabalho, interrompido até mesmo em sua fase inicial. Algumas medidas têm sido adotadas para remediar a situação, dentre elas, as tentativas de contato com o paciente, mesmo após maior número de faltas do que as permitidas pela clínica, dispostas em contrato, mediante avaliação do caso e das justificativas para as 
ausências aos atendimentos. Contudo, na maioria das vezes, o paciente acaba sendo desligado do processo devido ao fato de haver uma grande lista de pessoas em espera, pois, ao mesmo tempo em que muitos iniciam a psicoterapia, desligando-se após poucas sessões, encaminhamentos continuam chegando, a cada semana, indicados pelas demais instituições dos Municípios próximos à clínica, como escolas, centros de saúde e o Escritório Modelo de Advocacia (EMA) outro serviço disponibilizado pela UNIVALI.

Tal busca possivelmente ocorre porque há poucos locais de atendimento psicológico gratuito disponíveis para as camadas populares, haja vista que as equipes de unidades básicas e de hospitais gerais e demais serviços públicos de saúde não contemplam os profissionais da Psicologia. Essa questão remete ao fato de as políticas públicas de saúde não considerarem o serviço psicológico essencial - exemplo claro de tal fato é a ausência de psicólogos nas equipes básicas do PSF, compostas por profissionais da Medicina, da enfermagem e da odontologia, e que se configuram como porta de entrada para o Sistema Único de Saúde (Bandeira, Freitas, \& Carvalho Filho, 2007). Entretanto, houve, por parte dos psicólogos, omissão quanto à construção de seu espaço de atuação desde a regulamentação da Psicologia como profissão no Brasil. Bock (2003) alerta que a Psicologia tem se preocupado pouco com as questões sociais, tendo se isentado de projetos nessa área e marcado sua trajetória como reprodutora de ideologias da classe dominante; a autora ressalta que é preciso "compreender as relações sociais e as formas de produção da vida como fatores responsáveis pela produção do mundo psicológico" (p. 27).

Com relação à especificidade das demandas, o maior número de pessoas em lista de espera é de crianças. Em 2007, a maior quantidade de encaminhamentos para atendimento referiu-se a crianças entre 2 e 12 anos de idade, informação que possibilita discutir dois aspectos importantes desse contexto: a precariedade de serviços de saúde psicológica para a infância, haja vista que, conforme dados referentes ao mês de agosto de 2007, obtidos através da lista de pacientes que aguardam atendimento psicológico, das 108 pessoas em lista de espera, 101 são crianças, e, ao mesmo tempo, o fato de que, em muitos casos, a vinda da criança para a psicoterapia é uma "porta de entrada" para esse serviço, pois, na maioria das vezes, quem permanece em processo psicoterápico é um de seus responsáveis.

As principais queixas dos pais estão relacionadas a questões disciplinares, como dificuldade de impor/aceitar limites, tanto em casa quanto na escola, dificuldades de aprendizagem, medo ou nervosismo. Quando tais queixas são apresentadas ao serviço de Psicologia, nota-se um forte apelo, por parte dos pais, para que seus profissionais "resolvam" os problemas das crianças e as "corrijam", para que "parem de dar trabalho". Nesse sentido, Castro (1998) considera que

querem (os pais) que a psicoterapia transforme o filho em um bom cumpridor dos seus deveres e obrigações, em um filho responsável, bom, que não incomoda (e bom porque não incomoda). Consideram que, na medida em que o filho aprender a obedecer e a fazer o que é certo, seu problema de limites será resolvido. (p. 6)

Nessa situação, os pais esperam uma intervenção do serviço de Psicologia. Entretanto, é preciso que os estagiários esclareçam que o seu compromisso primordial deve ser estabelecido com a criança, o sujeito que se submete à psicoterapia. Essa postura marca uma ruptura que caracterizou fortemente a Psicologia em seu momento inicial como ciência e profissão, a saber: ter como ponto de partida a visão 
clássica de psicopatologia, baseada numa concepção de homem ahistórica e no modelo biomédico, uma concepção de saúde mental pautada na dicotomia normal/ anormal que buscava o enquadramento de comportamentos desviantes e não desviantes, uma prática que pretendia o ajustamento dos indivíduos na sociedade (Schneider, 2002). A abordagem existencialista tem, nesse sentido, permitido aos estagiários ampliar sua compreensão sobre os indivíduos que buscam atendimento psicológico, tendo em vista que o psicoterapeuta que adota essa perspectiva percebe o sujeito em sua totalidade, indo além de práticas que reduzam o paciente ao seu diagnóstico, ou seja, que se relacionem com o sujeito, prioritariamente, a partir de suas dificuldades concretas. Dessa forma, não é possível acatar o desejo e o pedido dos pais para que as crianças sejam "corrigidas", deixando de manifestar atitudes e comportamentos não compreendidos ou aceitos pelos adultos.

Assim, observou-se, nas intervenções realizadas na clínica, a suma importância, na etapa inicial do processo psicoterapêutico, de um período de avaliação da real necessidade de a criança permanecer em psicoterapia. Nesse momento, então, os pais foram chamados a comparecer ao atendimento para serem esclarecidos sobre alguns aspectos da infância e do desenvolvimento humano - como as particularidades da infância e da adolescência, caracterizadas como um período de intensa aprendizagem e, portanto, da inserção das mediações fundamentais que dão início à construção do projeto de ser dos indivíduos. Objetivou-se, assim, conscientizálos de seus próprios desejos, necessidades e dificuldades, que, muitas vezes, se refletiam nas expectativas que tinham dos filhos, mas que não poderiam ser satisfeitas através da sua "correção". Em muitos casos, o paciente deixou de ser, então, a criança e passou a ser os adultos, tendo em vista que conseguiam, a partir da psicoterapia, compreender que a maneira como se movimentavam no mundo interferia e mediava a forma como a criança se construía e se movia no mundo. A partir de tal compreensão, muitas vezes tornaramse capazes de perceber que, ao realizar mudanças em si mesmos, elas se refletiam em mudanças na criança, já que ela e seus pais se constituem em uma relação de tessitura histórica, concretizada pelas relações vividas; outras vezes, são os adultos que solicitam tal troca, porque sentem necessidade de mudar alguns aspectos de sua vida e de sua personalidade.

As intervenções junto aos pais das crianças atendidas foram possíveis a partir da compreensão de que, nascendo corpo e consciência, a criança é lançada em uma família, um espaço social no qual os outros têm expectativas a seu respeito: do que deve gostar, de como deve se comportar ou de que papel deve desempenhar no grupo familiar. Devido à sua estruturação psicofísica, ela é um ser em relação, sempre voltada para o meio externo. Ainda que, num primeiro momento, a criança não se diferencie dos outros e dos objetos e nem os diferencie entre si, as pessoas que a cercam lhe conferem uma identidade, pois o conjunto de expectativas criado pelos outros se desdobra no modo como eles se relacionarem com ela, lançando-a em um espaço existencial. Assim, os outros podem tratá-la com carinho ou com indiferença, escutar o que ela pede ou ignorá-la, lançarIhe olhares de aprovação ou de reprovação a partir de seus atos, identificá-la como boazinha, quieta, querida, chata ou maleducada, proporcionando-lhe contornos existenciais que constituem o início de seu processo de humanização (Castro \& Schneider, 1998).

Outro aspecto importante a ser destacado é que a CIABS vem se tornando referência para os atendimentos psicológicos no Município, principalmente para crianças, haja vista que os encaminhamentos são realizados 
Segundo

Peduzzi (2001),

profissionais que

organizam seus

atendimentos

a partir de

uma atuação

integrada ou

interdisciplinar

desenvolvem

uma articulação

das ações e

uma interação

dos agentes

que compõem

a equipe de

trabalho, criando

oportunidades

para o

estabelecimento de uma

intervenção

caracterizada

pela elaboração

conjunta de

linguagens, de

objetivos, de

propostas e

até mesmo de

culturas comuns. por profissionais de diversas áreas, que trabalham em outras instituições de saúde, e também por organizações de outros setores, como os Conselhos Tutelares, as escolas e o Recanto do Pré-Adolescente Municipal (REPAM). Com relação ao encaminhamento de adolescentes, adultos e idosos, eles são realizados, em grande maioria, por médicos que atuam na mesma clínica e também em outras unidades de saúde. As queixas, nesses casos, são variadas, incluindo complicações das relações familiares, das relações amorosas e da sexualidade, doenças temporárias e crônicas, casos de câncer, de violência física e sexual, experiências de alucinações visuais e auditivas e de pensamentos suicidas. Pode-se inferir que tal abrangência de demandas e de público está relacionada à escassez de espaços e de serviços públicos de saúde oferecidos à população. Considera-se que haja, ainda, uma lacuna nas atividades de prevenção e de promoção da saúde, acarretando a busca dos serviços de Psicologia apenas no momento em que as dificuldades já estão instaladas. Em todos esses casos, porém, apesar da complexidade e da necessidade de acompanhamento minucioso, a Psicologia tem conseguido oferecer um espaço privilegiado de desenvolvimento da psicoterapia, em que o paciente pode encontrar estratégias para lidar e superar os impasses que o trazem à clínica. Isso ocorre na medida em que o sujeito tem a possibilidade de redefinir seu projeto, realizando mudanças em sua forma de ser e de agir no mundo que lhe permitam fazer escolhas cotidianas a partir de uma reflexão crítica.

É importante, ainda, destacar a lacuna encontrada na clínica em questão no que se refere à intervenção interdisciplinar da equipe de saúde. Nos casos mais graves, quando o paciente necessita de medicação, de psicotrópicos ou de reabilitação física em função de acidentes e/ou de doenças, como câncer, por exemplo, há necessidade de maior diálogo entre os estagiários atendentes e os profissionais que os encaminham, ou seja, considerar os processos de saúde/ doença fenômenos coletivos, históricos e multideterminados implica uma atuação integrada da equipe de saúde - psicólogos, psiquiatras, fisioterapeutas, enfermeiros e médicos especialistas.

Segundo Peduzzi (2001), profissionais que organizam seus atendimentos a partir de uma atuação integrada ou interdisciplinar desenvolvem uma articulação das ações e uma interação dos agentes que compõem a equipe de trabalho, criando oportunidades para o estabelecimento de uma intervenção caracterizada pela elaboração conjunta de linguagens, de objetivos, de propostas e até mesmo de culturas comuns. Há, assim, a elaboração de um projeto assistencial comum, "construído por meio da intrincada relação entre execução de intervenções técnicas e comunicação dos profissionais" (p. 106). As equipes assim organizadas contêm, dessa forma, os fundamentos de trabalho que caracterizam o que Nina (1995) denomina equipes interdisciplinares, pois nelas há integração e convergência, na medida em que cada profissional observa as relações de sua disciplina com as demais - ou seja, não há justaposição das profissões -, sem, no entanto, negligenciar o terreno de sua especialidade. Realizando um trabalho a partir dessa perspectiva, com vistas à saúde integral e a uma abordagem biopsicossocial, acreditase que seja possível conquistar a melhoria de qualidade de vida e o direito que todo cidadão tem de receber atenção e cuidados que lhe garantam atendimento global (Martins \& Rocha Júnior, 2001).

\section{Considerações finais}

Compreende-se, assim, que, embora a teoria existencialista fenomenológica de Jean-Paul Sartre (1978a, 1978b, 1994, 1997), juntamente com a compreensão de 
Schneider (2002), tenha dado conta de abarcar a diversidade da demanda que se apresenta à Psicologia na Clínica Integrada de Atenção Básica à Saúde, seu trabalho ainda tem sido desenvolvido de forma isolada pela Psicologia, ou seja, sem que sua atuação seja articulada e planejada com os demais profissionais da área da saúde que nela realizam seu trabalho, pois a integração com tais áreas é exercida somente no momento do encaminhamento de pacientes. A interdisciplinaridade tem sido alcançada, mais comumente, nas atividades de promoção da saúde, realizadas através dos estágios em Psicologia educacional, por meio de projetos como, por exemplo, os de capacitação das equipes de agentes comunitários de saúde do Programa de Saúde da Família, em que os encontros são planejados e coordenados por profissionais da Psicologia, da enfermagem, da Medicina e da fisioterapia. A importância do investimento no trabalho interdisciplinar baseia-se na consideração de que uma clientela submetida à equipe interdisciplinar organizada tende a uma atitude mais colaborativa e participante em seu próprio tratamento, com aumento da capacidade de gestão de seus próprios recursos e de sua saúde. Acredita-se, assim, que uma maior integração entre as especialidades oferecidas pela clínica possa auxiliar na diminuição da desistência dos atendimentos antes do término do processo psicoterapêutico. Contudo, esse é o grande desafio das profissões que atuam nesse contexto e, em especial, da Psicologia, para o qual seria necessário criar instrumentos de comunicação e de diálogo entre as disciplinas, ampliando as possibilidades de compreensão de cada caso.

Finalmente, pelo exposto neste artigo, considera-se imprescindível que o número de profissionais de Psicologia nas unidades básicas de saúde seja ampliado, para que uma quantidade cada vez maior de pessoas possa ter acesso ao conhecimento e às práticas que essa ciência vem desenvolvendo ao longo dos anos e para que tenham, efetivamente, a possibilidade de contribuir para o desenvolvimento humano e social. Acreditase, assim, que a presença de psicólogos em tal espaço possibilite - principalmente através da compreensão da saúde como uma construção coletiva, envolvendo indivíduos e sociedade - o desenvolvimento de uma atuação em saúde capaz de abarcar os indivíduos em sua complexidade e dinamicidade como seres biopsicossociais. 


\section{Zuleica Pretto*}

Mestre em Psicologia, docente do Curso de Psicologia da Universidade do Sul de Santa Catarina (UNISUL)

\section{Fabíola Langaro}

Psicóloga, mestranda em Psicologia pela Universidade Federal de Santa Catarina (UFSC)

E-mail: flangaro@hotmail.com

\section{Geórgia Bunn Santos}

Psicóloga, psicoterapeuta da Espaço Clínica da Família

E-mail: georgia1004@hotmail.com

\section{*Endereço para envio de correspondência:}

Avenida Campeche, 1157, bloco A1 ap. 206 Campeche - Florianópolis, SC Cep 88063-300

E-mail: zuleicapretto@yahoo.com.br

Recebido 05/12/2007 Reformulado 30/01/2009 Aprovado 26/02/2009

\section{Referências}

Bandeira, M., Freitas, L. C., \& Carvalho Filho, J. G. T. de. (2007). Avaliação da ocorrência de transtornos mentais comuns em usuários do Programa de Saúde da Família. Jornal Brasileiro de Psiquiatria, 56(1), 41-47.

Bock, A. M. B. (2003). Psicologia e compromisso social. São Paulo: Cortez.

Brasil (1988). Constituição da República Federativa do Brasil. Brasília, DF: Senado Federal.

Canguilhem, G. O. (1982). Doença, cura e saúde. In G. O. Canguilhem, O normal e o patológico. Rio de Janeiro: Forense Universitária.

Castro, D. J. (1998). A importância dos limites no desenvolvimento infantil. Trabalho apresentado no II Colóquio de Psicologia Fenomenológica - Existencialista, Florianópolis.

Castro, D. J., \& Schneider, D. R. (1998). Contribuição do existencialismo moderno para a psicologia social crítica. Cadernos de Psicologia, 8, 139-149.

Kahhale, E. M. P. (2003). Psicologia na saúde: em busca de uma leitura crítica e uma atuação compromissada. In A. M. Bock (Org.), A perspectiva sócio-histórica na formação em psicologia (pp. 161-191). Petrópolis, RJ: Vozes.

Kujawa, H., Both, V., \& Brutscher, V. (2003). Direito à saúde com controle social. Passo Fundo, RS: Fórum Sul de Saúde (PR, SC e RS) / Centro de Educação e Assessoramento Popular de Passo Fundo (CEAP).

Martins, D. G., \& Rocha Júnior, A. (2001). Psicologia da saúde e o novo paradigma: novo paradigma? Psicologia: Teoria e Prática, 3(1), 35-42. Trabalho apresentado no I Congresso de Psicologia Clínica, Universidade Presbiteriana Mackenzie, São Paulo.
Ministério da Saúde. Secretaria Nacional de Assistência à Saúde. (1990). ABC do SUS - Doutrinas e princípios. Brasília, DF: Autor.

Nina, M. D. (1995). A equipe de trabalho interdisciplinar no âmbito hospitalar. In M. F. P. Oliveira, \& S. M. C, Ismael. Rumos da psicologia hospitalar em cardiologia (pp. 39-47). São Paulo: Papirus.

Peduzzi, M. (2001). Equipe multiprofissional de saúde: conceito e tipologia. Revista de Saúde Pública, 35(1), 103-109.

Sartre, J.-P. (1978a). O existencialismo é um humanismo (Coleção Os Pensadores). São Paulo: Abril Cultural.

Sartre, J.-P. (1978b). Questão de método (Coleção Os Pensadores). São Paulo: Abril Cultural.

Sartre, J.-P. (1994). A transcendência do ego. Lisboa: Colibri.

Sartre, J.-P. (1997). O ser e o nada (14. ed.). Petrópolis, RJ: Vozes.

Schneider, D. R. (2002). Novas perspectivas para a psicologia clínica: um estudo a partir da obra "Saint Genet: Comédien et martyr", de Jean-Paul Sartre. Tese de Doutorado defendida no Programa de Pós-Graduação em Psicologia Clínica, Pontifícia Universidade Católica de São Paulo, São Paulo.

Sponchiado, J. I. (1989). A mulher no segundo sexo. Dissertação de Mestrado, Universidade do Estado de Santa Catarina, Florianópolis.

Trafani, M. A. R. R. (1992). Método fenomenológico existencialista. Florianópolis: Nuca Ed. Independentes. 